eCommons@AKU

May 2018

\title{
Percutaneous Non-Stenting Approach for Distal Simultaneous Multivessel Acute Coronary Occlusions
}

\author{
Nasir Rahman \\ Aga Khan University, nasir.rahman@aku.edu \\ Bilal Hussain \\ Aga Khan University, bilal.hussain@aku.edu
}

Follow this and additional works at: https://ecommons.aku.edu/pakistan_fhs_mc_med_cardiol Part of the Cardiology Commons

\section{Recommended Citation}

Rahman, N., Hussain, B. (2018). Percutaneous Non-Stenting Approach for Distal Simultaneous Multivessel Acute Coronary Occlusions. JCPSP:Journal of the College of Physicians and Surgeons--Pakistan., 28(5), 398-400.

Available at: https://ecommons.aku.edu/pakistan_fhs_mc_med_cardiol/49 


\title{
Percutaneous Non-Stenting Approach for Distal Simultaneous Multivessel Acute Coronary Occlusions
}

\author{
Muhammad Nasir Rahman and Bilal Hussain
}

\begin{abstract}
The occurrence of distal coronary lesions causing simultaneous occlusion of two coronary arteries in the setting of ST elevation myocardial infarction is a rare occurrence. This can occur due to simultaneous plaque rupture at more than one site or embolisation in coronary arteries. We describe a case of a middle-aged man who presented with acute inferoposterior lateral wall ST elevation myocardial infarction with simultaneous occlusion of distal left anterior descending artery and distal left circumflex artery on angiogram. The patient was treated with intracoronary streptokinase, followed by glycoprotein (GP) Ilb/Illa inhibitor and Factor X inhibitor (Rivaroxaban) with full resolution of flow in the distal vessels. Thus, coronary lesions, not amenable to stenting, can be dealt percutaneously, using a combination of old and newer pharmacological agents without stenting.
\end{abstract}

Key Words: Simultaneous coronary occlusions. Intracoronary streptokinase.

\section{INTRODUCTION}

The simultaneous occlusion of two coronary arteries in the setting of ST elevation myocardial Infarction is a rare occurrence and is estimated to occur in $2.5 \%$ of all primary PCl patients. ${ }^{1}$

Occasionally, such multivessel occlusions of coronary vessels can be at areas where stenting might not be feasible due to very small vessel or very distal vessel occlusion. These lesions pose a unique challenge to the interventional cardiologist. We, herein, report such a case of a patient with simultaneous distal occlusion of two coronary arteries in the setting of ST elevation myocardial infarction that were dealt with intracoronary streptokinase upfront separately in each vessel for restoration of flow, followed by glycoprotein (GP) Ilb/llla inhibitors infusion and then Factor $\mathrm{Xa}$ inhibitor (Rivaroxaban) with full recovery of patient.

\section{CASE REPORT}

A 57-year gentleman presented to the Aga Khan University Hospital, Karachi, Pakistan in May 2015 with Killip I Inferoposterior lateral STEMI (Figure 1A). ST segments did not show any response to sublingual nitrates in emergency room. His baseline investigations are shown in Table I. He was transferred to the cath lab for emergent coronary angiogram that showed simultaneous occlusion in distal left circumflex artery

Department of Medicine, The Aga Khan University Hospital, Karachi.

Correspondence: Dr. Muhammad Nasir Rahman, Assistant Professor, Section of Cardiology, Department of Medicine,

The Aga Khan University Hospital, Karachi.

E-mail: nasir.rahman@aku.edu

Received: June 23, 2017; Accepted: October 11, 2017.
(LCx) and apical left anterior descending artery (LAD). As the patient had borderline blood pressures, intracoronary nitroglycerin (IC GTN) was not given to rule out spontaneous coronary spasm. Due to the very distal location of the lesions, it was decided to use intracoronary streptokinase (SK) for revascularisation. $250 K U$ intracoronary SK was injected sequentially into the LAD and LCx over 3 minutes via aspiration catheter. Post-intracoronary SK, TIMI III flow was seen both in distal LAD and LCx (Figure 2). The ECG changes settled

\begin{tabular}{l|c|c} 
Table I: Investigations at admission. \\
\hline Investigations & Result & Normal Lab value \\
\hline Hemoglobin & $14.8 \mathrm{~g} / \mathrm{dl}$ & $12.0-15.0 \mathrm{~g} / \mathrm{dl}$ \\
Platelets & $290 \times 109 / \mathrm{L}$ & $150-300 \times 109 / \mathrm{L}$ \\
Creatinine & $0.9 \mathrm{mg} / \mathrm{dl}$ & Less than $1.2 \mathrm{mg} / \mathrm{dl}$ \\
\hline
\end{tabular}

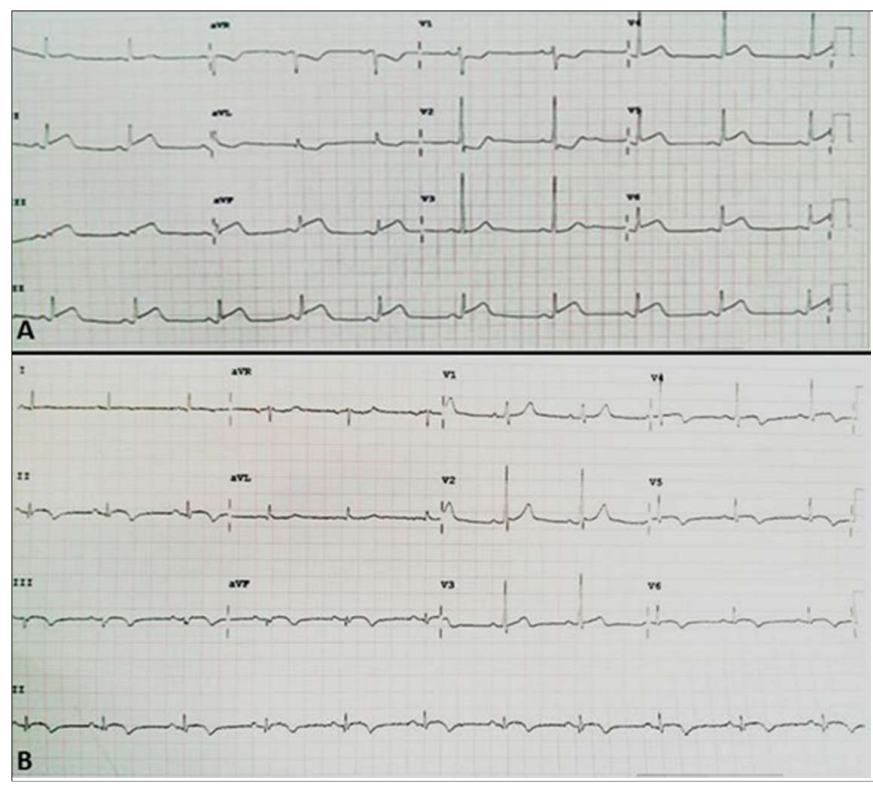

Figure 1: Electrocardiograms (ECG): $(A)$ at presentation; (B) after intracoronary streptokinase. 


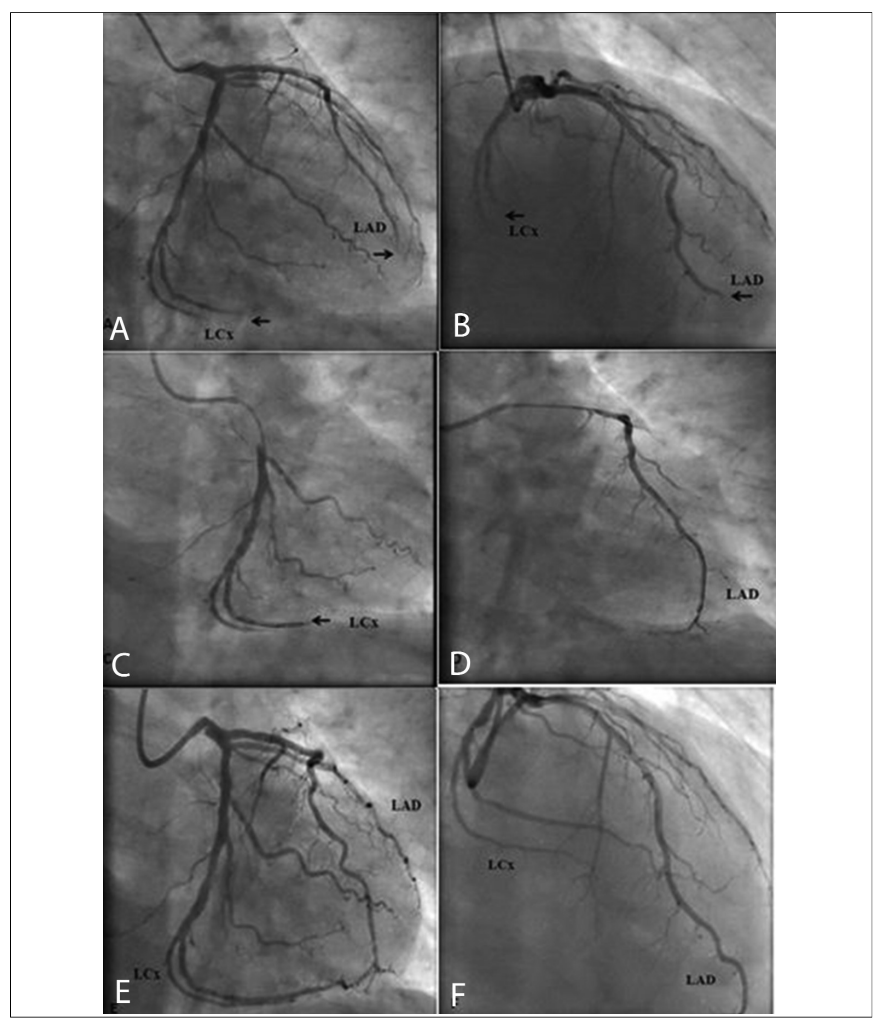

Figure 2: Coronary angiogram: (A) RAO caudal view showing occlusion of distal LAD and LCx branches; (B) RAO cranial view showing occlusion of distal LAD and LCx branches; (C) Intracoronary streptokinase injection into left circumflex artery; (D) Intracoronary streptokinase injection into left anterior descending artery; (E) RAO caudal view after intracoronary streptokinase showing flow in distal LAD and LCx; (F) RAO cranial view after intracoronary streptokinase showing flow in distal LAD and LCX.

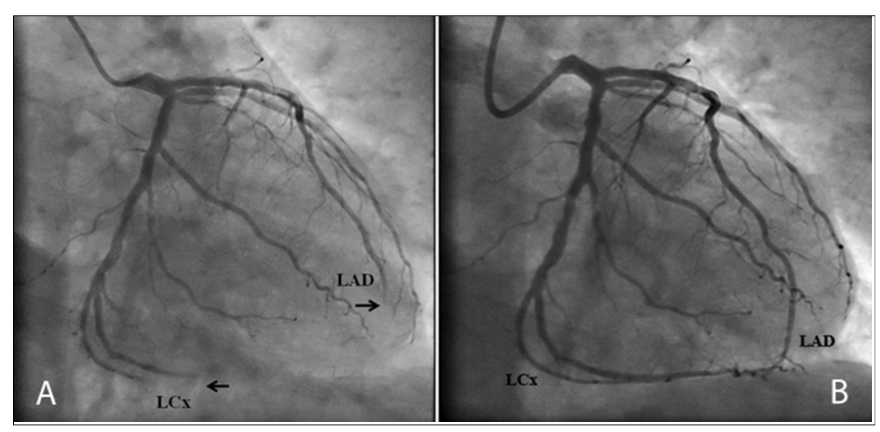

Figure 3: (A) Coronary angiogram pre-intracoronary streptokinase; (B) Postintracoronary streptokinase.
(Figure 1B) and the patient became pain-free. Patient was started on GP IIb/llla inhibitor infusion for 24 hours and then on tablet Rivaroxaban $10 \mathrm{mg}$ twice daily. The patient remained symptom-free during hospital stay. A trans-esophageal echocardiograph (TEE) was done which showed no evidence of vegetation or clot. A relook angiogram was done prior to discharge that showed TIMI III flow in LAD and LCx. The patient was discharged on dual antiplatelets (DAPTs) and Rivaroxaban $15 \mathrm{mg}$ once daily. Rivaroxaban was continued for 3 months and then he was kept on DAPTs. At one year follow-up, the patient is asymptomatic with full recovery of left ventricle function on echocardiograph.

\section{DISCUSSION}

Review of literature shows that simultaneous occlusion of more than one coronary vessel causing STEMI is unusual and often lethal associated with cardiogenic shock and high mortality. 1,2 Simultaneous occlusion of more than one coronaries may occur due to plaque rupture, embolisation, coronary spasm, hypercoagulable states such as malignancy, thrombocytosis and antithrombin III deficiency.3.4 Most of these patients are hemodynamically unstable with high incidence of cardiogenic shock and chances of life-threatening ventricular arrhythmias. ${ }^{5}$

A review of literature on the use of thrombolytics in the setting of STEMI with simultaneous multivessel occlusions on coronary angiogram shows four cases which were dealt with intracoronary (IC) thrombolytics (Table II). In these cases, use of IC thrombolytics was reserved with stenting, mostly for proximal coronary artery lesions. The most common combination for simultaneous occlusions of vessels was LAD and right coronary artery (RCA). Urokinase appeared as the thrombolytic agent of choice.6-8 To our knowledge, there is no reported case where an IC thrombolytic therapy with SK was used for distal occlusions in the setting of STEMI caused by simultaneous occlusion of more than one coronary vessels.

Though, IC SK was used in the pre-stenting era, but its use was associated with complications such as systemic

Table II: Review of case reports of patients with ST elevation myocardial infarction with simultaneous occlusion of two coronary arteries treated with intracoronary thrombolytics.

\begin{tabular}{|c|c|c|c|c|c|c|c|c|}
\hline Study & Year & Age & Presentation & Vessel involved & Treatment & $\begin{array}{l}\text { Dose of intracoronary } \\
\text { thrombolytics }\end{array}$ & $\begin{array}{l}\text { Immediate results } \\
\text { of intervention }\end{array}$ & Outcome \\
\hline Hamada [11] & 1989 & 59 & Inferior STEMI & $\begin{array}{l}\text { Proximal left anterior } \\
\text { descending and right } \\
\text { coronary artery }\end{array}$ & $\begin{array}{l}\text { Intracoronary urokinase } \\
\text { to } L A D \text { and } R C A\end{array}$ & $\begin{array}{r}720,000 \text { IU to RCA } \\
480,000 \text { IU to LAD }\end{array}$ & $\begin{array}{l}60 \% \text { residual stenosis } \\
\text { in RCA, } 50 \% \text { residual } \\
\text { stenosis in LAD }\end{array}$ & Alive \\
\hline Yoshitomi [12] & 1998 & 34 & Anterolateral STEMI & $\begin{array}{l}\text { Proximal left anterior } \\
\text { descending and proximal } \\
\text { left circumflex coronary } \\
\text { artery }\end{array}$ & $\begin{array}{l}\text { Stenting of LAD and } \\
\text { Intracoronary prourokinase } \\
\text { to } L C x\end{array}$ & 3,000 IU to LCx & $\begin{array}{l}30 \% \text { distal stenosis in } \\
\text { LAD and LCX }\end{array}$ & Alive \\
\hline Hosokawa [13] & 2001 & 33 & Inferolateral STEMI & $\begin{array}{l}\text { Proximal left anterior } \\
\text { descending and mid } \\
\text { right coronary artery }\end{array}$ & $\begin{array}{l}\text { Stenting of RCA and } \\
\text { Intracoronary tisokinase } \\
\text { in LAD }\end{array}$ & $6,400,000 \mathrm{IU}$ & $\begin{array}{l}\text { TIMI III flow in RCA, } \\
\text { LAD showed residual } \\
\text { thrombus }\end{array}$ & Alive \\
\hline Turgeman [14] & 2007 & 44 & $\begin{array}{l}\text { Anteroinferior STEMI } \\
\text { with cardiogenic shock }\end{array}$ & $\begin{array}{l}\text { Proximal left anterior } \\
\text { descending and proximal } \\
\text { right coronary artery }\end{array}$ & $\begin{array}{l}\text { Thrombus aspiration } \\
\text { followed by intracoronary } \\
\text { urokinase in the left and } \\
\text { right coronary system }\end{array}$ & 125,000 IU & $\begin{array}{l}\text { TIMI III flow in LAD } \\
\text { and RCA }\end{array}$ & Alive \\
\hline
\end{tabular}

${ }^{*} \mathrm{RCA}=$ Right coronary artery; LAD = Left anterior descending artery; LCx = Left circumflex artery; IU = International units; STEMI = ST elevation myocardial infarction . 
bleeding and bleeding at the puncture site. These complications were more pronounced if dose of SK exceeded 200,000 IU. The other major cardiac complications of IC SK administration were reperfusion arrhythmias. With the advent of stenting, the use of IC SK became limited. However, in 2007, Murat in his study used IC SK after stenting in patients undergoing primary percutaneous intervention. ${ }^{9}$ The dose used by Murat et al. was $250 \mathrm{KU}$, at which the chances of SK associated complications were significantly low. However, in that study IC SK was used after stenting to achieve better flow. The authors used this dose of SK (250KU) separately for each vessel upfront without any complications. This case showcases the fact that this dose of SK can be used safely in more than one vessel occlusion.

This case report is an unusual occurrence of STEMI with simultaneous mutlivessel occlusions that might have occurred because of possible simultaneous plaque rupture in multiple coronary arteries or due to embolisation of a proximal clot. In the patient, the TEE did not show any evidence of proximal clot; however, the possibility of clot embolisation from a proximal source cannot be ruled out completely. An intravascular ultrasound (IVUS) might have helped in delineating the etiology. However, due to the distal location of lesions, it was not performed during the angiogram. The history and laboratory workup did not suggest any hypercoagulable state. Another differential was spontaneous coronary spasm in the distal vessels; however, patient did receive sublingual nitrates in emergency room, but due to low blood pressure during the procedure, IC GTN could not be used. Furthermore, we found in our procedure that flow was only restored after fibrinlolytic therapy suggesting a thrombotic event rather than spasm. Other possibility in this case was spontaneous plaque rupture occurring at more than one distinct site simultaneously leading to ST-elevation myocardial infarction. Therefore, to prevent re-occlusion of arteries, we decided to keep our patient initially on GP IIb/IIla inhibitors and then on Rivaroxaban for few months.

Rivaroxaban, a coagulation Factor Xa inhibitor, is approved for use in nonvalvular atrial fibrillation for the prevention of stroke and systemic embolism. However, in patients with acute coronary syndromes, low-dose Rivaroxaban is known to reduce the risk of the composite end-point of death from cardiovascular causes, myocardial infarction, or stroke.10 As spontaneous plaque rupture at multiple sites was suspected in our patient, we used a higher dose of Rivaroxaban. This approach helped in our patient's management without recurrence of any clinical events and full recovery of left ventricular function.

This case is unique in which there was simultaneous occlusion of two distal vessels, which were dealt with old (SK, DAPTs and GP Ilb/llla) inhibitors and new pharmacological agents (Rivaroxaban) combined with percutaneous intervention for full recovery of patient.

Though rare, ST-segment elevation myocardial infarction with simultaneous multiple coronary artery occlusions may occur. In patients with distal coronary lesions not amenable to stenting, the use of IC SK initially and then followed by GP IIb/IIla inhibitors and newer anticoagulants based on clinical condition and risk factors of patients can provide good immediate angiographic results with full recovery of left ventricular function in these patients on follow-up.

\section{REFERENCES}

1. Pollak PM, Parikh SV, Kizilgul M, Keeley EC. Multiple culprit arteries in patients with ST segment elevation myocardial infarction referred for primary percutaneous coronary intervention. Am J Cardiol. 2009; 104:619-23.

2. Kanei Y, Janardhanan R, Fox JT, Gowda RM. Multivessel coronary artery thrombosis. J Invasive Cardiol 2009; 21:66-8.

3. Terada $\mathrm{H}$, Satoh $\mathrm{H}$, Uehara A. Multivessel coronary thrombosis, acute myocardial infarction, and no reflow in a patient with essential thrombocythaemia. Heart 2000; 83:E10.

4. Tu CM, Hsueg $\mathrm{CH}$, Chu KM. Simultaneous thromboses of double coronary arteries in a young male with antithrombin III deficiency. Am J Emerg Med 2009; 27:e3-6.

5. Mahmoud A, Saad M, Elgendy IY. Simultaneous multi-vessel coronary thrombosis in patients with ST-elevation myocardial infarction: a systematic review. Cardiovasc Revasc Med 2015 May; 16:163-6.

6. Yoshitomi $\mathrm{Y}$, Kuramochi M, Kojima S. Acute myocardial infarction with simultaneous occlusions of two major coronary arteries in a young man. Clin Cardiol 1998; 21:140-2.

7. Hosokawa S, Hiasa $Y$, Miyamoto $H$, Suzuki N, Takahashi $T$, Kishi $\mathrm{K}$, et al. Acute myocardial infarction showing total occlusion of right coronary artery and thrombus formation of left anterior descending artery. Japanese Heart $J$ 2001; 42:365-9.

8. Turgeman $\mathrm{Y}$, Suleiman $\mathrm{K}$, Atar S. Multivessel acute coronary thrombosis and occlusion - an unusual cause of cardiogenic shock. J Invas Cardiol 2007; 19:E278-80.

9. Murat Sezer, Hüseyin Oflaz. Intracoronary streptokinase after primary percutaneous coronary intervention. $N$ Engl $J$ Med 2007; 356:1823-34.

10. Gibson CM, Chakrabarti AK, Mega J, Bode C, Bassand JP, Verheugt FW, et al. Reduction of stent thrombosis in patients with acute coronary syndromes treated with rivaroxaban in ATLAS-ACS 2 TIMI 51. J Am Coll Cardiol 2013; 62:286-90. 